\title{
The Application of Differentiated Instruction in Reading and Writing to a Boy with Autism in Early Childhood Education. A Case Study
}

\author{
Makrina Zafiri ${ }^{1, *}$, Alexandra Konstantinidou ${ }^{2}$, Vassiliki Pliogou ${ }^{2}$ \\ ${ }^{1}$ Foreign Language Office, Aristotle University of Thessaloniki, Greece \\ ${ }^{2}$ School of Education, Metropolitan College Thessaloniki, Greece
}

Received September 3, 2019; Revised October 28, 2019; Accepted November 5, 2019

\begin{abstract}
Copyright $\odot 2019$ by authors, all rights reserved. Authors agree that this article remains permanently open access under
\end{abstract} the terms of the Creative Commons Attribution License 4.0 International License

\begin{abstract}
A number of research findings show that, because of the phenomenon of classroom heterogeneity, in our days, there is a need for the application of differentiated instruction. The latter is a modern teaching approach, which has as its ultimate objective the provision of the best possible education for pupils with special educational needs, including autism. By applying differentiated instruction, the teacher can enhance the learning skills of students as well as contribute to their cognitive and socio-emotional development. The purpose of this research is to investigate the effectiveness of differentiated instruction in the writing and reading skills of a boy with autism in early childhood education. To this end two types of research methodologies were applied, qualitative research (semi-structured interviews) and action research through a series of activities, based on the principles of differentiated instruction. The results of this research showed that the application of differentiated instruction has produced positive results, for the boy who has autism, in both reading and writing.
\end{abstract}

Keywords Differentiated Instruction, Autism, Early Childhood Education, Writing, Reading

\section{Introduction}

In recent years, in Greece and abroad, there has been a rapid change in the composition of the school classes [1-3]. More particularly, students with special educational needs seem to present a strong heterogeneity in the classroom [4]. The latter usually display specific skills but also special needs during their educational careers [5]. This brings to the fore a new challenge for the entire educational community. A modern response to this challenge is differentiated instruction, in which each teacher is called upon to diversify and adapt his/her teaching so that all students in the class can respond to it, depending on each student's learning potential thus achieving a smooth integration of these students in the classroom [6,7].

Differentiated instruction is a teaching approach addressed to all the students of a conventional school class, especially to those students with special needs. In particular, this approach to teaching refers to the appropriate design of teaching materials, emphasizing upon the student's needs and the curriculum [8]. When implementing this teaching approach, the teacher makes an effort to motivate students' learning through a wide range of tools, materials and interests. Through this teaching process, students have the opportunity to learn individually thus acquiring better results [9]. At the same time, the variations in the process and content which this teaching approach offers, allow students to enjoy their learning outcomes and, perhaps, even to improve their academic performance [10].

\section{Objectives of the Research}

This research is a case study and its purpose is to explore the application of differentiated instruction to a five-year-old nursery school boy with autism so as to help him to develop his reading and writing skills. In particular, in order to answer to the aforementioned purpose, specific research questions were formulated. These research questions are the following:

1. Can the implementation of differentiated instruction bring about positive results to a kindergarten boy with autism?

2. Can the implementation of differentiated instruction bring about positive results to the writing skills of a boy with autism in early childhood education? 
3. Can the implementation of differentiated instruction bring about positive results to the reading skills of a boy with autism in early childhood education?

In order to answer to the aforementioned research questions, two research methodologies were adopted, namely, qualitative research through the use of semi-structured interviews from the mother of the boy, his nursery school teacher and his special education teacher, who provided him with parallel teaching and learning support, and secondly through action research, and more specifically, through a series of lessons and activities, which were based on the principles of differentiated instruction. Differentiated instruction was applied because the Greek educational system expects teachers, who have pupils with learning difficulties in their nursery school classes to apply differentiated instruction so as to facilitate their students' learning. This is the reason why the researchers opted for differentiated instruction, in the first place, in the sense that it was not a choice but an obligation on behalf of the researchers [11].

\section{The Concept of Autism}

The Greek legislation on Special Education Needs (SEN) explicitly states that any kind of disability will be deemed as part of a human being's existence but also as a complex socio-political phenomenon [11]. Within such a context, the stance taken by the state is that it should prevent people from being deprived of their right to education and participation in the state's social life. Of equal importance is the role played by the school community which develops appropriate teaching objectives according to the needs of each group of students [12]. In the present research our interest focuses on a boy who is in kindergarten and who falls within the spectrum of autism.

Autism was unknown, as a concept, until the middle of the last century. However, until then, doctors, psychologists and educators had focused their attention on studying the causes of autism as well as on how to deal with autism. They were strongly supported by the parents of autistic children who were determined to fight for their children's rights [13]. In developed countries, in particular, there was a coordinated effort for the enactment of legislation which set forth the rights of people with autism in areas such as the health sector, in education and the wider society sector. They created diagnostic services which also included health care centers, psychological support, education for special needs students, daily work, and lifelong protection for people with autism [14].

\section{The Definition of Autism}

In a brief review of the existing literature one finds that it is difficult to give only one definition of "autism" because there is heterogeneity in the number of scientific sources dealing with autism [15]. However, a scientifically accepted definition is that of the American Psychiatric Society, according to which autism is a developmental disorder which directly affects the nervous system of the afflicted person and is characterized by a limited amount of social interaction as well as by stereotypical and recurrent behaviors [16].

\subsection{Forms of Autism}

Recently, the term "Pervasive Developmental Disorders (PDD)" has been replaced by "Autism Spectrum Disorder (ASD)," including those with high functioning autism and the Asperger syndrome [16]. According to [17], there is great difficulty in assessing autistic children because there are many different types of autism. The PDD includes the syndromes listed below, as well as names that have occasionally been used to denote any one of them. More specifically, in the fourth edition of the Diagnostic and Statistical Manual of Mental Disorders, five types of PDD are included: autistic disorder (Kanner's Syndrome, childhood autism, infantile autism, etc.), Rett syndrome, Disruptive Disorders in Childhood, Dementia, Heller's syndrome, etc.), Asperger syndrome (Autistic Psychopathic Disorder, Childhood Schizoid Disorder, etc.) and Pervasive Developmental Disorders which have not otherwise been defined $[15,16]$.

\section{Characteristics of Autism}

Even today, the diagnosis of autism is based on the characteristics of the patient's behavior rather than on medical examinations. Thus, the basic characteristics which should be present, so that autism can be diagnosed, as a syndrome, are firstly, disruption in a person's social interaction, secondly, lack of communication and, thirdly, a limited imagination [18]. The basic characteristics presented above are the "Trinity of Disorders" and in combination with the repetitive stereotypical activities which occur, and which may either be simple or complex, are the early indications of autism $[19,20]$. The intensity and nature of the disorder in the aforementioned areas differ and their interaction has, as a result, various clinical manifestations. However, there are also other characteristics which are considered typical but which we may not be able to pin-point, as their manifestation is not a prerequisite for the diagnosis of autism [21]. Some of these are speech problems, visual impairment and lack of eye contact, problems in hand and foot coordination, as well as problems in imitating movements, unusual reactions to sensory experiences, strange emotional reactions and various disorders in the boy's daily functions and in his/her physical development $[22,23,24,25]$. 


\section{Rationale}

In recent years, significant efforts have been made to formulate various hypotheses and theories in order to elucidate the factors which cause autism. However, the etiology of autism is not yet known, but there are indications that many factors may be responsible for this. In particular, environmental factors, the old age of parents when giving birth to an autistic child as well as the exposure of the infant to valproic acid. In addition, comparative research data show potential genetic factors such as heredity factors which range from $37 \%-90 \%$ [16, 26, 27, 28]. Additionally, research findings reveal that genetic and metabolic syndromes such as the Fragile $\mathrm{X}$ Syndrome (FXS) also play an important role [29]. Quite a few researchers also support that perinatal and external factors as well as, neuroanatomic factors may also be responsible $[29,30]$. Finally, immunological factors such as those in which children have Pervasive Developmental Disorders, stimulate brain mast cells resulting in local allergies and neurotoxicity [31]. Research on the identification of these causes continues until today.

\section{Teaching Reading and Writing Skills to Children with Autism}

In terms of the reading and writing skills of students with autism, the Greek school curriculum proposes that autistic students in nursery school should be given learning opportunities to develop their graphophonemic (GP) awareness. This means they should be trained to match the graphemes of a Greek word to its corresponding phonemes [32]. As concerning writing skills, autistic students should be given opportunities to copy words or symbols that serve functional needs or which correspond to their interests. In other words, they should be given opportunities to write the corresponding letters of the sounds they hear, capital and lowercase letters, control their size, shape and orientation to form words, and finally to write combinations of letters thus expressing words and phrases [32]. The teaching approach which has been proposed is differentiated instruction [11].

\section{Differentiated Instruction - Theoretical Background}

At present, the pedagogical challenges in education in terms of efficiency within a context of social equality which exists in multidimensional heterogeneous classes, suggest that there is a need to apply teaching methods that are appropriate to the social and educational needs of today's society [10]. These challenges can be effectively addressed only through differentiated instruction which is a teaching approach based on the theory of constructivism and social constructivism [33]. This approach is considered to be the cornerstone of today's modern, genuine and flexible education which focuses on the student himself or herself [34]. This means that differentiated instruction is a didactic approach in which teaching is shaped and adapted according to the student's needs, abilities, interests and learning pace, allowing the student to develop independently as a learner [35]. Differentiated instruction is based on the concept of the application of different teaching methods and approaches, as well as the application of different means and procedures which will pave the way for successful learning [36]. The differentiated approach to language teaching is also proposed by the Greek educational system [11] as the most appropriate approach for pupils with learning difficulties.

The holistic approach to differentiated instruction should take into account a number of factors which interact with each other [38]. In particular, some factors act directly and decisively at a micro-level (internal differentiation) [39]. The latter is related to the performance, skills, abilities, interests and wishes of the individual student, and concerns the way in which the teaching and learning process is organized. Other factors operate at a macro-level (external differentiation), for example, the educational policy of a country or state and the types of schools which exist, the curricula, the linguistic, social, cultural and political characteristics of each educational system [40].

Moreover, differentiated instruction enables the educational community to intervene on important facets of the educational process. The main axes upon which differentiated instruction revolves are four and relate to the teaching context, the teaching method /approach, the product produced and the learning environment [41]. As concerning the first axis, differentiated instruction refers to what all pupils should learn, in other words the basic knowledge and skills which they should acquire, as well as other necessary information which they should have access to so as to learn [42]. The second axis refers to the diversity of activities in which the learner will become involved in order to process and understand the content and thus acquire knowledge [37]. The third axis focuses on the application and presentation of the newly acquired knowledge or skill through a final project or a piece of work which the student is called upon to present using a variety of means and materials [43]. Finally, the fourth axis focuses on the way in which the teaching context is formulated including the classroom as a physical space (for example the classroom's desk and chair arrangements, other furniture or materials which may be used, the aesthetics of the classroom, rich stimuli such as colors on the walls of the classroom, posters, projects produced by the students' of a particular class, etc.), in order to create an appropriate environment which will strengthen the effort of each student [44]. 


\subsection{Matters Concerning Assessment in Differentiated Instruction}

Assessment plays a very important part in differentiated instruction, as it improves and enriches the process itself by taking into account the continuous progress which is made by the pupil and the individual profile of the pupil [46]. As the first step, the teacher is asked to make an initial assessment (this is the preliminary phase) during which he / she will collect data on the pupil's readiness level in order to design the appropriate teaching material which he or she will use [47]. Then follows the formative assessment stage, which is a process of gathering information on the pupil's learning needs so as to decide upon what will improve the pupil's understanding of the material which is being taught and which will lead $\mathrm{him} / \mathrm{her}$ to successful learning [48]. Finally, the process is completed through final assessment in which the pupil's knowledge is assessed and through which the success or the failure of both the teaching materials and teaching process is evaluated [49].

\subsection{The Effectiveness of Differentiated Instruction}

In light of the above theory it is necessary to mention that the success of differentiated instruction is not always 'a given fact' in the teaching process. The aforementioned stance refers to those teachers who possess the necessary knowledge concerning differentiated instruction, as there are some teachers who think that by changing some of their teaching practices, they are, in fact, applying differentiated instruction, which is a fallacy [50]. The efficacy of differentiated instruction is documented in theory and practice. There are a number of studies which support that differentiated instruction can bring about positive results in pupils' learning, especially pupils with learning difficulties [37]. Nevertheless, differentiated instruction is strongly supported by its followers [51,3] and is considered an effective means of teaching in many educational systems around the world [52].

\section{The Research}

The purpose of this research was to investigate the application of differentiated instruction in reading and writing to a boy with autism in early childhood education. The Greek educational system for nursery schools, supports the need for students who are attending their final year in nursery school (which is the last year in which students attend nursery school before they graduate and enter the first class or primary school), to be able to recognize the letters of the alphabet, in this case the Greek alphabet, and to be able to write these letters, the aforementioned also includes students with learning difficulties [11].

More specifically, on the one hand this research focused on the National Curriculum for Nursery School Students with Autism and on the other hand, in the design and development of language learning activities and the application of differentiated instruction for the acquisition of specific learning skills (in particular writing and reading skills) by a boy with autism. Although there is extensive literature on this issue $[29,52,30]$, the researchers, nevertheless, chose to conduct this research because there was a research gap in Nea Pella, an area three-quarters of an hour away from Thessaloniki, which is the second biggest city in Greece. The purpose of this research study is to explore the application and effectiveness of differentiated instruction to a five-year-old nursery school boy with autism so as to help him to develop his reading and writing skills. Therefore, in order to investigate the issues above, the following research questions were set:

1. Can the implementation of differentiated instruction bring about positive results to a kindergarten boy with autism?

2. Can the implementation of differentiated instruction bring about positive results to the writing skills of a boy with autism in early childhood education?

3. Can the implementation of differentiated instruction bring about positive results to the reading skills of a boy with autism in early childhood education?

The following people participated in this research, a five-year-old boy with autism, his mother, his nursery school teacher and a special education teacher who provided a parallel co-teaching support to him. The research was conducted in the area of Skydra, in Pella, between January and April of 2018. Both parents gave their signed consent for this research and the mother also participated actively in the research through the semi-structured interview which was conducted. Both the nursery school teacher and the special education teacher who provided parallel co-teaching support to the boy gave their consent when they participated in the semi-structured interview.

\section{The Boy's Profile}

The official diagnosis of the Center for Differential Diagnosis and Support took place in May 2016, and according to the members of the board, S., who is the boy under scrutiny (and whose name we will not mention for ethical reasons but whom we will refer to as 'boy'), has "Pervasive Developmental Disorders (PDD)". He achieved an IQ of 63 and is at a mental age of 4 years, 3 months on the Leiter International Performance Scale [73]. The boy is five years old today and is the smallest member of his family and is one and a half years younger than his brother. $\mathrm{He}$ is a boy who is willing to work and is honest and who also has a good memory span and perception. More particularly, when tested upon his 'Verbal Span' the boy heard the examiner speak a sequence of words at the rate of 
one word per second. For each trial, a fixed sequence was randomly presented from a set of nine words, all of which were single-syllable, high-frequency concrete nouns (arm, boat, brush, chair, dress, knife, mouse, ring, tree). After each sequence was spoken the boy was immediately presented with a $3 \times 3$ grid containing nine-line drawings corresponding to the set of nine words, and was instructed to touch the pictures (in the aforementioned drawings) as the words were spoken. For each trial the arrangement of the pictures in the grid changed so as to prevent the boy from using a fixed visual representation of the array to help encode the word sequence. The changing array also introduced a visual search component to the task. The boy was given two different trials of each sequenced length, which ranged from two to seven words. One point was given for each trial which was correct. Testing was discontinued when the boy failed both trials of any one sequence length. The mean score for the Verbal Span test was $\mathrm{MN}=6.75 . \mathrm{SD}=4.32$.

The first time he spoke was after the age of four, and after the intervention of his speech therapist and his occupational therapist. However, he began to write shortly before his fourth birthday, but until recently, he could not hold his pen and pencil appropriately. Also, his narrative and descriptive skills were not in line with his chronological age. His vocabulary is incomplete and his articulation presents phonological and articulatory errors. He responds to his name; he is able to follow simple commands, and he is also able to mimic very easily. Before the intervention, difficulties could be traced to his communication skills, as he responds monosyllabically to the questions which are directed to him (or uses one or two words to answer questions which have been posed to him), thus showing his reluctance to engage in conversation and/or to make a deliberate conversation for social purposes. He does not like changes in his life and he does not perceive danger. Before the intervention he had no problem expressing his needs but he did have a problem in expressing his emotions. In addition, he had problems with his diet and he also seemed to enjoy eating chocolate a lot.

The boy attends nursery school in the area in which he lives. He has a good relationship with his peers; he can work and cooperate with them but he cannot have a two-way communication. He also lags behind with some forms of games, namely 'symbolic games', but he seems to like the narration of a fairy tale and often participates in the narration. He, very willingly, takes part in all school events; he is able to memorize and tell his poems by heart and participates in all school performances. He also adheres to and abides by the rules of the class and the school; he follows the school program with the help of his special education teacher and is particularly interested in routine activities.

Moreover, as regards his cognitive skills, he knows and can name colors and shapes; he understands the concept of space, time, size and quantity, the names of several animals, and of some fruits and vegetables. Additionally, he can write letters and numbers which he sees; count the number of objects; he recognizes numbers as written symbols and can also recognize and write the letters of the Greek and the English alphabet. However, he has difficulties in placing flashcards and pictures of stories (which he hears or which are read to him) in chronological order and in a logical sequence. Finally, he has difficulties in sketching things and copying letters.

\section{Research Method}

Two kinds of research methods were applied in this research, qualitative research (through semi-structured interviews) and action research. In qualitative research non-quantifiable data concerning social behavior, social processes and phenomena as well as social trends, are investigated [56]. Research data on qualitative methods can be evaluated as verbal sets and can constitute a publicly accepted opinion [57]. Thus, the purpose of qualitative research is not the examination of prefixed assumptions but the 'discovery of new dimensions' of the object or subject under scrutiny [58].

Researchers who adopt this method emphasize on the ways in which the social world is interpreted, experienced and reproduced by its participants within a multitude of daily interactions and practices in which they participate [59]. Consequently, they (the researchers of the present research) sought to examine the phenomena under investigation through the participants' perspectives, experiences and stories. In particular, the semi-structured interviews provided an opportunity (to the researchers) to investigate the respondents' views within an interpretive framework but also allowed the researchers to record their (the participants') personal experiences [60]. All of the above justify the choice of the aforementioned methods within the context of this research. At the pre-intervention stage a semi-structured interview was conducted. An interview guide was formulated consisting of six main axes: a) Demographics; b) The profile of the boy; c) The Methods/Approaches used to conduct the teaching procedure; d) The Teaching Methods and Approaches which were initiated by the teachers so as to develop the reading and writing skills of the boy, e) The teaching and learning assistance received by the boy from another teacher, and g) The need for the diversification of the teaching process.

Similarly, after the intervention a post-semi-structured interview was conducted. The interview guide consisted of four parts: a) Changes which occurred in reading and writing, b) Changes which occurred in other fields of learning, c) The role played by differentiated instruction in the changes which were made; and (d) A report on the role played by each participant in enhancing this change. Each interview lasted about 20-60 minutes and the place in 
which the interview was conducted was chosen by each participant individually.

As concerning the action research which was conducted, it is suggested that this type of research is a small-scale intervention in the real world and, at the same time, it examines its effects [60]. In fact, there are scholars who argue that the purpose of action research is not simply the understanding and interpretation of the world around us but its change [53, 62]. This means that this kind of research can be carried out in almost all environments in which a problem involves individuals and situations and requires an immediate solution, or in cases in which changing a subject's characteristic can bring about a desired result [63]. This is the reason why action research was conducted for the purposes of this research.

More specifically, with regard to conducting action research, in the present study, ten lesson plans were prepared the contents of which were based on the principles of differentiated instruction. These lesson plans were structured according to the demands of the Greek National Curriculum for students with autism who are attending nursery school. The activities were prepared along the guidelines proposed by the Ministry of Education and Religious Affairs, as well as along the lines followed by some of the books which are accepted by the Ministry and which are specially written for students in early childhood education in Greece. The first lesson plan, followed by its activities, was applied to the boy in the form of a pre-test to diagnose his language level. It is worth noting that the first two lesson plans were the pilot phase of the research. Another nine lessons followed consisting of various activities which related to the subject under scrutiny namely, reading and. writing Finally, the boy was given a post-test so as to examine his language and cognitive level but also to evaluate his progress, following the application of differentiated instruction. It is worth noting that all the activities which were carried out were based on the interests of the boy and were designed to meet his needs. All the activities, of each lesson plan, were aimed at verifying the effectiveness of differentiated instruction on the autistic boy.

\section{Credibility and Validity}

In every research the concepts of reliability and validity are important not only during the course of the process but also during the collection and presentation of the results [55]. Thus, in this research, the above concepts were also verified through triangulation. The latter is an auxiliary practice which was first proposed in the social sciences and its original aim was to enhance its validity and credibility. Triangulation was applied in this research because we needed to give a comprehensive picture of the boy under scrutiny aiming at the integration and fuller exploration of the subject under consideration [61]. This practice also provides a deeper and broader understanding of the research. More specifically, the auxiliary practice, mentioned above, was adopted in this research, through the collection of data from three different sources (the mother, the nursery school teacher, and the special education teacher) in order to gather diverse and perhaps different answers which will enhance the interpretative capacity on the subject under scrutiny [56].

\section{Ethical Issues}

In recent years, ethical issues have become more and more important to research. These issues hold a dominant position in the research process and are an integral part of it. This may be because the researchers' involvement with the personal details of the participants is long-lasting. Thus, in order to ensure the ethical integrity of this research, the researchers avoided risk; respected human dignity, namely the appropriate treatment of the participants; and, finally, justice, meaning that the processes were fair and moral, as the researchers did not exploit the participants and the situation which they were in [62].

Thus, in this research all principles (in the code of ethics) were abided by and respected. In particular, to assure that the research will be conducted morally, in the sense that the participants' rights to anonymity will not be breached; the researchers presented them with a consent letter and a 'consent form' [63]. The latter is the document signed by the individual saying that he or she agrees to participate in the research and that he or she voluntarily consents to the research and may withdraw from it whenever he or she wishes, having first read the consent letter which was given to him/her and which informed him/her about the nature of the research [64]. For the student's participation, in the research, consent was obtained from both parents.

\section{The Research Results}

In order to analyze the qualitative data which were gathered so as to answer the research questions, the researchers chose to follow the steps taken by [65], namely, 'thematic analysis'. Initially, audio files of the interviews were transcribed. The researchers then collected the data and organized them into electronic files each of which was assigned a unique number which corresponded to the unique number attributed to each participant. Next, the aforementioned researchers carried out multiple readings of the contents of the semi-structured interviews. At the same time, they encoded the text. The next step was the categorization of identical codes, in other words identical answers which were elicited from the participants. Thus, the analysis of qualitative data, through the semi-structured interviews, before and after the intervention, resulted in six main axes before the intervention, and in four main axes after the intervention. To each axis a name was given, depending on the contents of the answers. The above 
procedure was carried out in order to further investigate the participants' answers regarding the subject under discussion and to link the specific results with the wider bibliography which exists in the field of inclusive education.

\section{The Analysis of the Results}

\subsection{The Semi-Structured Interviews before the Intervention}

The responses of the semi-structured interviews before the intervention were grouped into six axes each of which dealt with a specific thematic framework. More particularly, the first axis addressed the cognitive level of the three participants, while the second axis referred to the characteristics which implied that the boy under scrutiny was autistic. Next, the third axis included the way in which the teaching was conducted, so far, and the fourth axis focused on the learning strategies that were activated to develop the boy's reading and writing skills. The last two axes, namely five and six, examined the teaching aid the boy received from his teacher and the need to differentiate his/her teaching accordingly.

As concerning the answers of the first axis which dealt with the educational level of each participant, the mother replied that she had graduated from a Technological Educational Institute (TEI) and more specifically from the School of Electrical Engineering, the nursery school teacher holds two degrees, one from the School of Philology and the second degree is from the School of Early Childhood Education, whereas the special education teacher said that she is a nursery school teacher with a postgraduate degree in Special Education. The two teachers were also asked about the content of the lessons which they were taught at a post-graduate level and more particularly their knowledge on autism. Both the nursery school teacher and the special education teacher agreed that their basic education did not include knowledge on autism. However, they attended workshops, lectures, etc., from which they were taught, in general, about children with special needs.

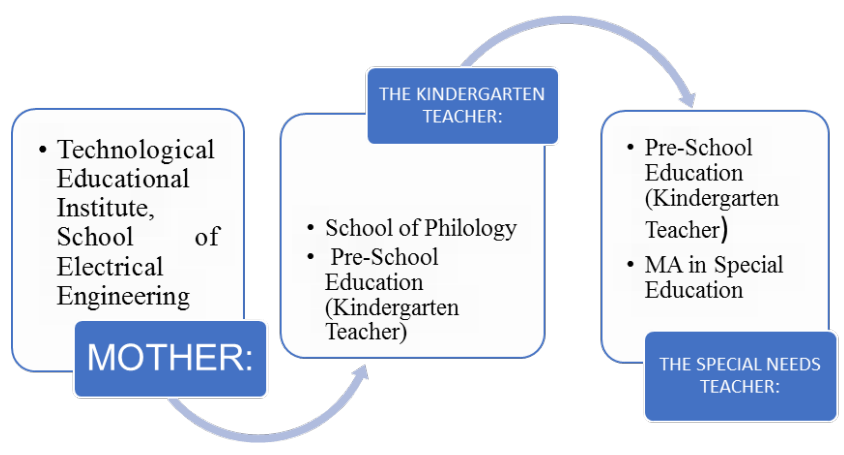

Figure 1. Qualifications of participants

As concerning the answers of the second axis, the participants were asked about the characteristics that imply that the boy is autistic. According to the mother, the first suspicions about the existence of autism arose when her child did not respond to questions which were directed to him. She also added that he lagged behind in his language skills and that he had difficulties in his social interactions. She also mentioned that he repeated many of his movements and that he had eating disorders. In addition, he liked routine and reacted negatively when something changed in his daily schedule, he also became frustrated by loud sounds and did not perceive potential danger, and that many times he isolated himself from the rest of the family. The above are in line with the views of the nursery school teacher and the special education teacher. However, the special education teacher also added that the boy had no eye contact, that his attention was often distracted and that he lagged behind in 'symbolic games'.

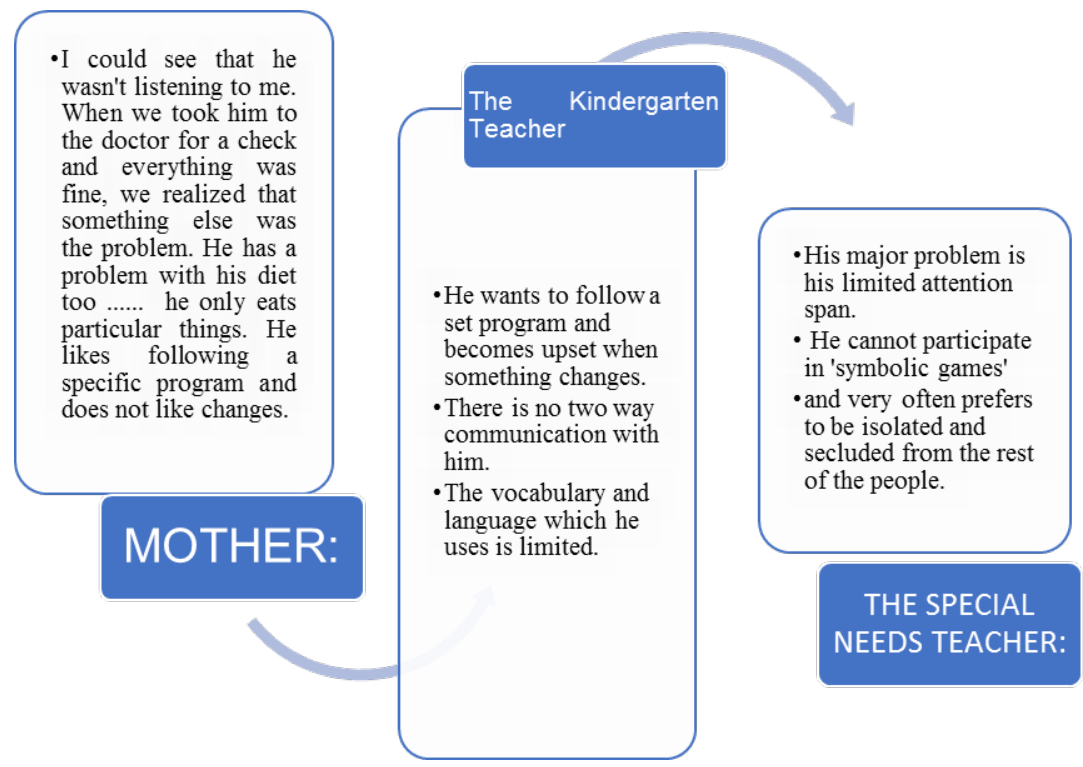

Figure 2. Characteristics implying autism 


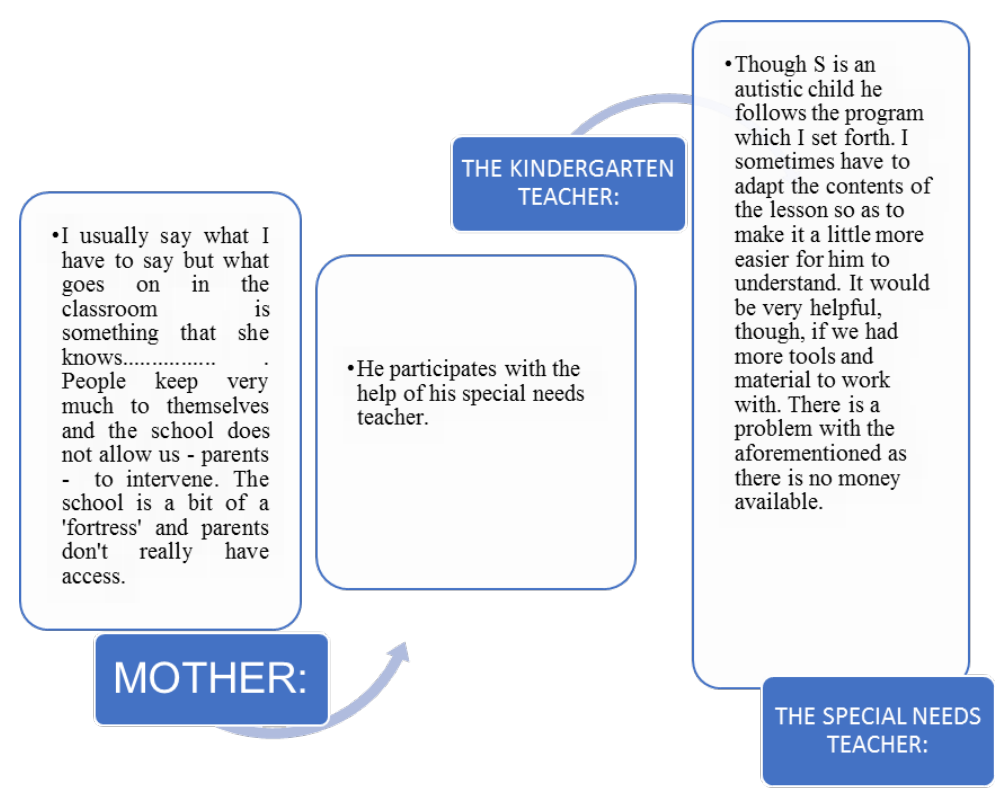

Figure 3. Teaching language to an autistic student in Kindergarten

As concerning the answers of the third axis, the participants responded to questions such as, how should the lesson within a nursery school class be conducted and, how should students with autism be taught in order to facilitate their learning. More particularly, the mother argued that she often asked the special education teacher to teach her son specific things which she wished him to learn. She nevertheless, could not say much about what was going on in the nursery school class because the teacher did not inform her regularly. She also complained that the nursery school, which her son goes to, did not permit much contact between the parent and the nursery school teacher. The nursery school teacher replied that the boy normally participates in the classroom activities, as he is guided and assisted by the parallel support which he receives from his special education teacher. Finally, the special education teacher argued that in the parallel support which she provides to the boy, she generally follows the guidelines of the National Curriculum for pupils with autism and that there is always a necessity to guide and help him. She also added that to help the boy understand things better she always uses flashcards and pictures, digital games, tablets and PCs. She also believes that the lesson would be more effective and creative if more materials were available.

The responses to the fourth axis include the learning strategies that are being activated by the mother, the nursery school teacher and the special education teacher in order to help the boy to develop his reading and writing skills. In particular, the mother replied that in order to strengthen the skills mentioned above, a blackboard is stuck on the fridge so that the boy can constantly be encouraged to read and write on it with chalk. She often dictates letters, one by one, in order for the boy to compose a word. In essence, this is a process in which the boy's knowledge of the written language emerges, becomes conscious, is systematized, and enables him to clarify the correspondence between letters and phonemes, and, thus, helps him to acquire the ability to write coherently, that is, to produce a letter by letter composition of his work.

The nursery school teacher claimed that she tries to teach, to all her students, that language is a means of social communication and that it is used as a code of communication by all people. Also, the nursery school teacher mentioned that in early childhood education there should be no mention made of reading and writing, in general, but of emerging literacies. Finally, the special education teacher reported that she teaches the boy reading and writing together or at the same time (in other words that she doesn't separate the one from the other).

As concerning the 5th axis, the three respondents answered questions which dealt with whether the boy received any help from another teacher at school besides his nursery school teacher. The mother replied that her child is receiving help from a special education teacher, which provides him with parallel support. The nursery school teacher responded that parallel support was, mainly, the reason why the boy was able to follow the activities of his nursery school class, as well as his school curriculum. Finally, the special needs teacher claimed that she helped the boy to become more effective in his learning. 


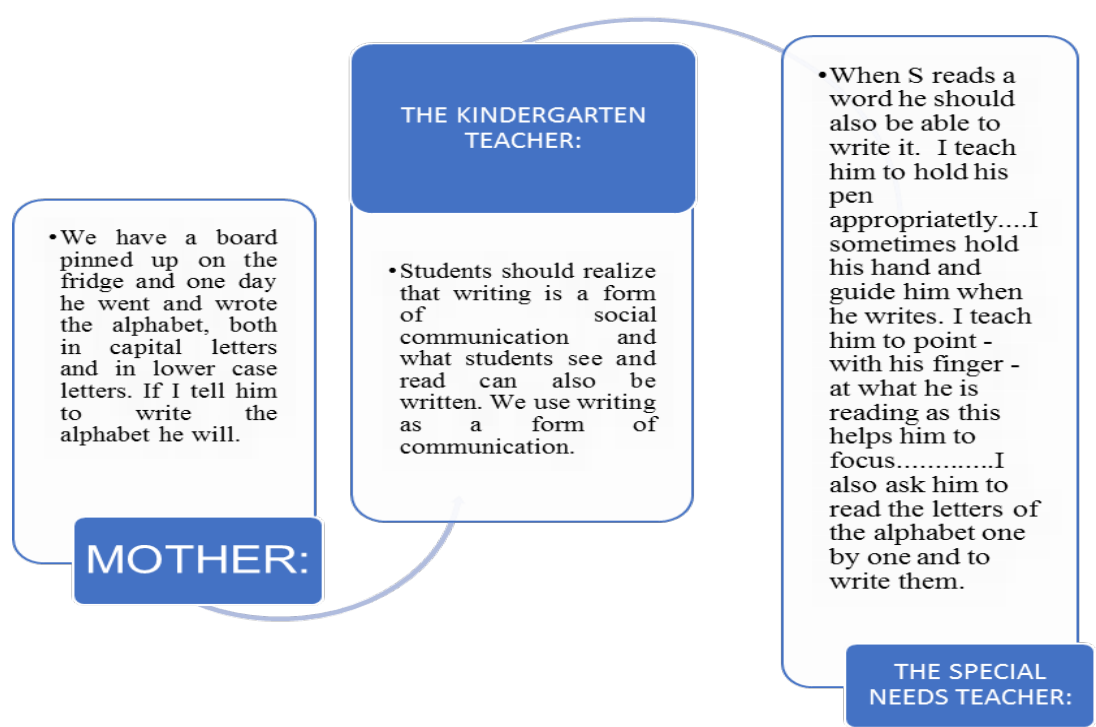

Figure 4. Learning strategies of the autistic student

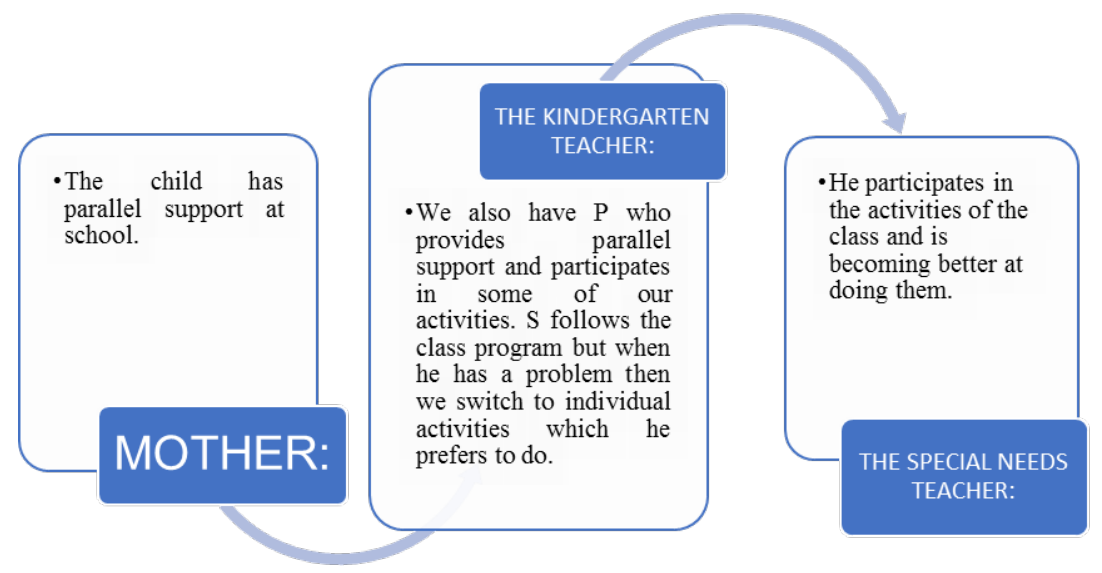

Figure 5. Extra aid in learning reading and writing skills

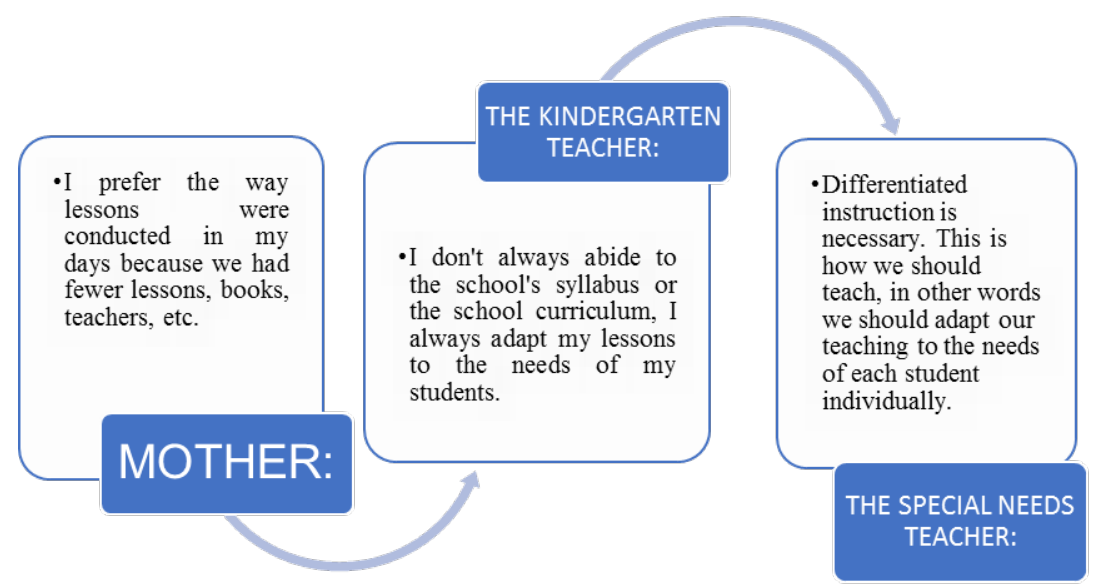

Figure 6. Alternative methods and approaches to teaching and learning 
The 6th and last axis include the interviewees' answers concerning alternative methods and approaches to teaching and learning. More specifically, when the mother was asked about what should be changed in the educational system, she responded that things were much better when she was a student because there were fewer books and lessons when she had to attend school; there were also fewer responsibilities for the students and fewer teachers per class. Also, the mother noted that she had no idea what differentiated instruction was. Both the nursery school teacher and the special needs teacher responded that they knew what differentiated instruction was. They also agreed that it was necessary because it (differentiated instruction) is tailored to the individual needs of each student. 15.2. The Analysis of the Action Research

As regards the action research which was conducted, the choice of each lesson plan's activities was based on the National Curriculum for students with autism in nursery school; on what some school textbooks proposed (in a slightly modified form to suit the needs and abilities of the boy); and, on the principles of differentiated instruction. We need to stress here that the activities which were given to the boy were tailored for his needs and interests and for the learning difficulties which he faced.

\subsubsection{1 st Lesson Plan "Traveling ... to the Alphabet"}

The teaching of the first lesson began with the narration of the story, 'Pipitsa travels ... to the alphabet'. Initially, the researchers showed the boy the front cover of the book, then they showed him the back cover of the book, the beginning and the end of the book, the title and the author. During the reading process, each time the page was turned, the boy immediately read the letter he looked at. However, although he knew the symbols of the alphabet, for some letters he asked the researchers which words begin with the particular letter that the page was showing. The moment one of the researchers put their finger under each word so as to read it the boy imitated their actions by putting his finger under the word so as to read it too.

When the boy was shown a board game [66] he was thrilled and shouted loudly: "Let's play!" Every time the dice of the board game fell upon a letter, the boy was able to produce the letter orally and was also able to give an example of a word which included the letter. After playing once on his own, he asked the researchers to play with him, saying: "Your turn now!" The researchers pretended not to find the letter to which the dice pointed to and asked for the boy to help. The boy responded immediately and, in this way, he managed to complete the board game on his own and in the end he asked if he could play the board game again.

In the last activity, the boy was asked to sort out the capital letters from the lower-case letters and to place the capital letters on the left-hand side of the column of an A4 paper and the lower-case letters on the right-hand side of the column. Every time he stuck a letter, he named it and specified whether it was a capital letter or a lower-case letter. The boy preferred sticking the letters around his house because as he said, "Letters should be close to their home".

\subsubsection{2nd Lesson Plan "A Letter ... A Story"}

The researchers played the video 'A Letter ... a Story' https://www.youtube.com/watch? $\mathrm{v}=2 \mathrm{VxBidHBalQ}$ on YouTube. This video tells a story about each and every capital letter of the alphabet. At the same time, the researchers asked the boy to name every letter he saw. Throughout the video, the boy was very excited and, to show his excitement, he sang and danced. After the YouTube video the researchers gave the boy a worksheet entitled 'I Recognize the Words'. More particularly, the boy was asked to circle the words which he saw with his wax-crayons. However, the boy seemed to have misunderstood the instructions, and began to copy the words. The researchers re-explained the instructions to him and the boy managed to finish the activity successfully.

\subsubsection{3rd Lesson Plan "Learning to Write and read My Name and Surname"}

On an A4 paper the researchers wrote the boy's name, in order to teach him the letters of which his name was composed. Then, on the worksheet which was given to him by the researchers' and which was divided into two boxes with different contents, the boy joined the dotted line which formed his name and surname with a color marker (in the first box) and was thus able to write his name and surname. Then, in the second box the boy wrote his name with a color marker by tracing the letters (ichnographically) which he had learned earlier. Finally, in the third and last box he composed his name by cutting out letters from a newspaper which the researchers had provided him with and then he placed these letters in the appropriate order so as to write his name.

\subsubsection{4th Lesson Plan "My Family"}

Initially, the researchers spread some pictures on the table and asked the boy who these pictures depicted. Then, after the researchers received the correct answers from the boy, they gave him pictures of his father, his mother, and his brother and asked him to read what was written below each picture. After he completed his reading, the researchers asked the boy to match the flashcards which he had with the corresponding photographs of members of his family. In the second phase the boy was asked to draw a member of his family on a piece of paper which had been placed within a frame. He was given the opportunity to choose which member of his family he wanted to draw. At the beginning he chose his mother but later he expressed his desire to draw his father, his brother and himself. In the third and last phase the researchers wrote on an A4 paper the word 'mother' as she was the first-person the boy wanted to draw and then asked him to form the word on his 
own using round stickers. The boy showed great enthusiasm and completed this activity successfully.

\subsubsection{5th Lesson Plan "Colors"}

Initially, the researchers narrated to the boy the fairy tale entitled 'The Colors'. Each page of the book describes one color. While the boy listened to the story, the researchers asked him to find the corresponding color from amongst an array of colored cartons which also contained the name of each color. Aided by the researchers the boy tried to read the color which he had picked out. He started by reading each letter separately and then he tried reading the whole word. In fact, when he read the word 'red' [ко́ккıvо], in his mother tongue, which also depicted the color red, the boy observed that there were two " $\kappa$ 's" in the (Greek) word red [ко́ккıvо]. Finally, in the second phase the boy wrote each color with his fingers using watercolors and then painted each animal picture, which was given to him, using the appropriate watercolors which were indicated next to each picture.

\subsubsection{6th Lesson Plan "The World of Vegetables"}

In the first phase of the sixth lesson the boy immediately took the fairy tale entitled 'The Vegetables' in his hands and began to browse through it. One of the researchers encouraged him to read the title with her. After reading the book the researchers placed real vegetables on the table. The boy immediately picked up the first potato and tried to match it with the picture depicting the potato. Then, one of the researchers began narrating the story again while, at the same time, the boy successfully matched the real vegetables with those of the pictures.

In the second and final phase of the specific work plan the boy was asked to write the title of the book 'The Vegetables' using liquid chocolate. The boy successfully copied the two words, namely, 'The Vegetables' and every time he wrote a letter, he named it.

\subsubsection{7th Lesson Plan "Domestic Animals"}

In the first activity of the seventh lesson one of the researchers read the title of the book to the boy namely "A Small Walk in the Farm". At the same time, the boy was asked to find the flashcard which depicts the animal on the corresponding page of the fairy tale. After the boy identified the flashcard and compared it to the picture on the page of the fairy tale, he also read the name of each animal that was written under each flashcard with the help of the researchers. Initially the boy began reading each letter of the word and then he read the whole word.

In the second activity the researchers placed the flashcards on the table and asked the boy to choose one of them. The boy chose the flashcard which depicts a cow. The researchers then asked him to look through the plasticized letters and to find the letters that make up the word 'cow'. After he found them, he hung them up, using wooden pins, on the ribbon that was tied between two wooden spoons. The process was completed after the boy had composed the words of all the animals.

\subsubsection{8th Lesson Plan "Feelings"}

In the eighth lesson, and without receiving any instructions, the boy took the letters out of their box and placed them in alphabetical order on his desk. After completing this task, the researchers explained that for today's activity he had to choose a tongue depressor upon which an emotion was written (in words). After choosing the tongue depressor which he wanted he was asked to place magnetic letters upon it which described the emotion that was written on the tongue depressor. With the completion of each word the boy was asked to choose the corresponding picture depicting the emotion he wrote. The boy succeeded in writing all five emotions (joy, love, terror, anger and sadness) and at the same time he managed to find the corresponding pictures

(https://paixnidikaidimiourgia.blogspot.gr/2017/12/blog-p ost_8.html).

\subsubsection{9th Lesson Plan "My Favorite Sport"}

In the first phase of the ninth lesson, the researchers gave the boy the card with the different sports and briefly explained the nature of each sport. At the same time, they asked the boy to read, with their help, the title of each lesson. The boy immediately responded. Initially, he began to call out each letter individually but then after that he read the whole word out aloud. The researchers then asked the boy if he could tell them what his favorite sport was choosing amongst those which were shown on the flashcards. The boy expressed his liking for football and then wrote his name next to the picture.

In the second phase the boy was asked to copy the name of his favorite sport from the flashcard which he saw on the internet. He hastened to point and call out the very word enthusiastically: "Letters on the computer!" Pictures that related to football appeared on the computer's screen and the boy was asked to choose one and to paint it on an A3 piece of paper. In the final phase, after painting a ball, he was encouraged to copy the name of the sport from the flashcard. He wrote the letters one by one thus forming the word and eventually completed the activity successfully.

\subsubsection{0th Lesson Plan "Easter with Its Red Eggs"}

In the first phase of the tenth and final lesson one of the researchers undertook the task of telling the boy the story "Tales of the Bible: The History of Easter" explaining - at the same time - the reason why Easter holidays exist. In this particular activity the boy wanted to hold the book himself and to turn the pages when the reading of each page was completed. In the second phase the boy was presented with an Easter Card and at the same time he was asked to read the contents of the card which were "Happy Easter", the boy began to read the letters one by one. Finally, the researchers asked him to 'write' the aforementioned 
"Happy Easter" wish with plasticine, on the table.

\subsection{Semi-Structured Interviews (After the Intervention)}

The responses of the semi-structured interviews, after the intervention, were grouped into four axes each addressing a specific thematic area. More particularly, the first axis discussed the changes observed in the child after the intervention, especially changes in his reading and writing skills, while the second axis dealt with changes in his other learning skills. The third axis referred to the role played by the application of differentiated instruction in order to make these changes come true. Finally, the fourth axis examined the role that each participant played so as to enhance these changes.
For the first axis the participants responded to the changes observed on the boy in terms of his reading and writing skills. More specifically, the mother replied that the boy could now write the alphabet, quite readily, and could also copy words. Moreover, with regard to reading, she argued that he could now recognize and read the words he was taught. The nursery school teacher replied that after the intervention the boy understands the letters of the alphabet a lot better; he holds his pencil appropriately; he writes a lot better and his speech has improved; he has also managed to enrich his vocabulary. What is mentioned above seems to coincide with what the special education teacher supports. The latter also added that with her help the boy slowly began to read words. She also stressed that she had seen a spectacular change in the boy's oral production.

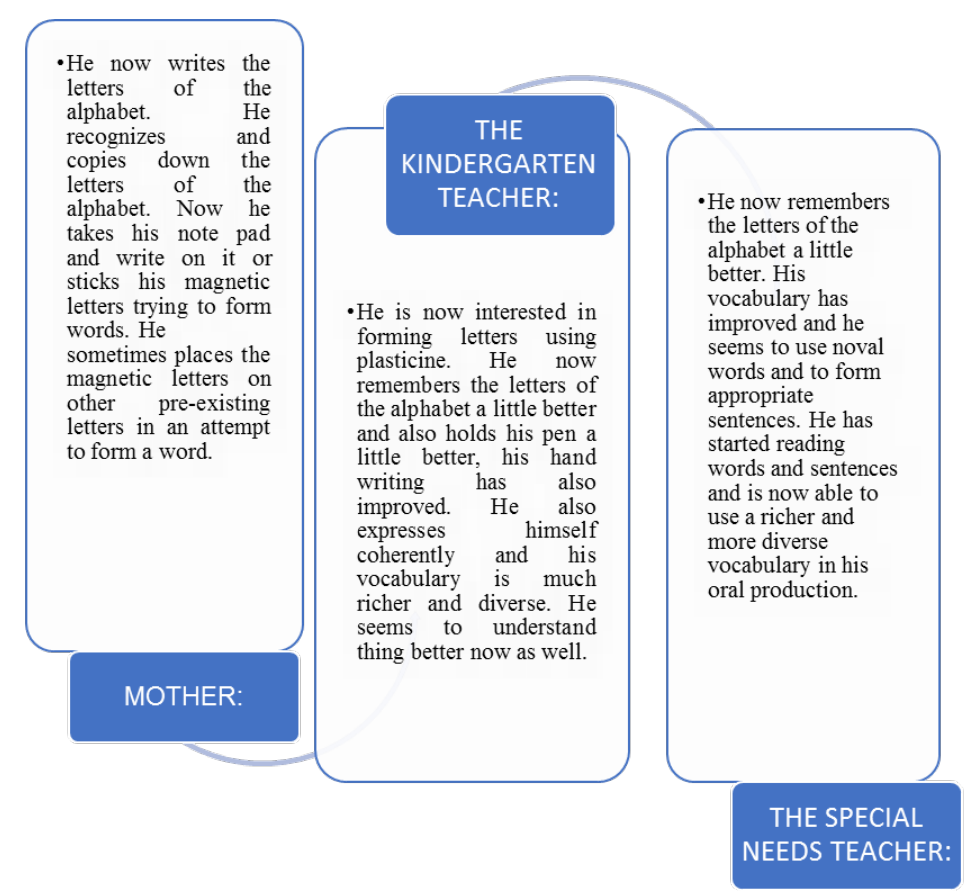

Figure 7. Changes observed in $\mathrm{S}$, in terms of his reading and writing skills

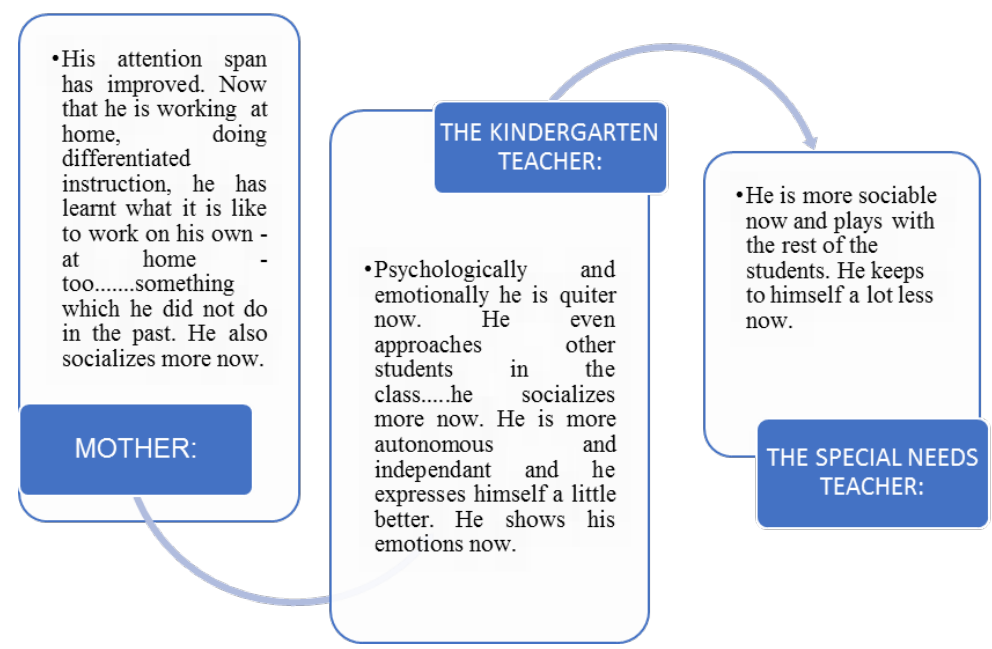

Figure 8. Changes observed in S's communication and other learning skills 
On the second axis the participants were asked about the changes they had observed on the boy's other learning skills which were independent of his reading and writing skills. In particular, the mother replied that the intervention and differential instruction which took place in the boy 's home helped him to understand what it was like to work at home, something which he had not done before. At the same time, she added that at the end of the ten lessons he started to socialize more. The mother's last words agree with those of the nursery school teacher and the special education teacher who said that they too noticed that the boy had greatly improved in his social skills and in his personal relationships with the people living around him. The nursery school teacher also added that she had seen an improvement in the boy's emotional and psychological stance as he now seems to be calmer and more autonomous than he was before but is also able to express his emotions more easily.

The third axis refers to the role that differentiated instruction has played in helping the boy advance linguistically and socially. More particularly, the mother replied that until now she did not know what differentiated instruction was. However, she confessed that this teaching approach had a positive effect on her child. She also believes that these lessons were very enjoyable and entertaining for the boy. The nursery school teacher replied that differentiated instruction played a decisive role in changing the way the boy thought and reacted. The special education teacher agreed with the nursery school teacher and stressed that all the activities played a very important role in developing the boy's reading and writing skills.

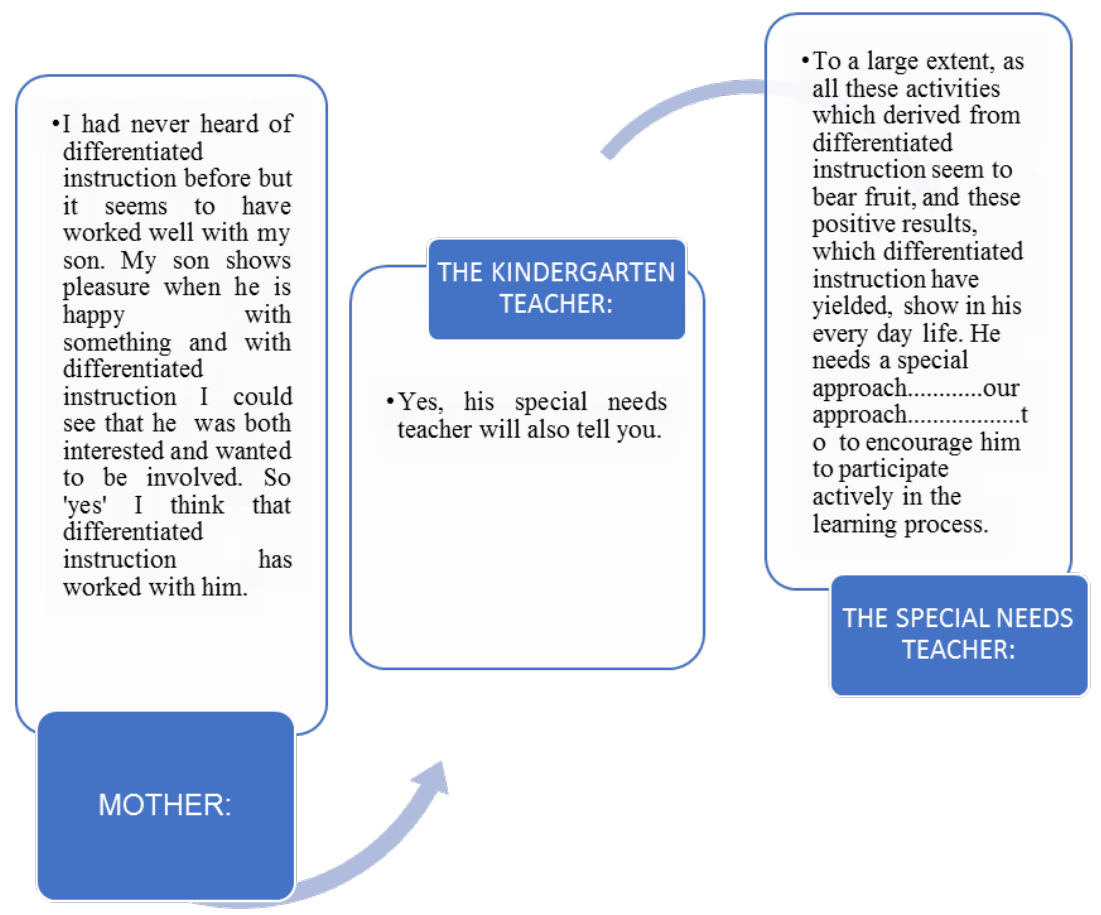

Figure 9. The role played by differentiated instruction

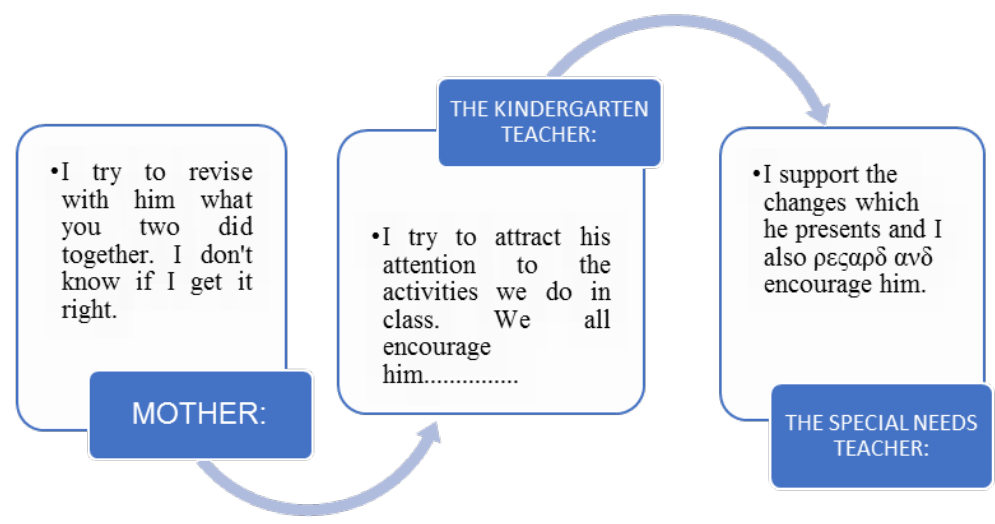

Figure 10. The role played by the participants 
The fourth and final axis contains the interviewees' answers on the role played by each participant in enhancing the changes mentioned above. In particular, the mother maintained that she constantly revised the activities the researchers did during the intervention with her son. However, she noted that, she does not always manage to revise them well with him as the boy is not as obedient with her as he is with the researchers.

The nursery school teacher replied that she always tries to attract the boy's attention to the activities that are being carried out in the nursery school classroom and adds that she constantly encourages him to participate but sometimes she also lets him work on his own. Finally, the special education teacher's response converges with the nursery school teacher's stance in the sense that she encourages him verbally, every day, by congratulating him, as a reward, when he shows progress.

\section{Discussion}

Based on the theory and practice of differentiated instruction, the present research answered positively to the purpose set in this research, proving the effectiveness of differentiated instruction and confirming its effectiveness on pupils with special education needs. In particular, through this research we realized that the application of differentiated instruction can bring about positive changes in the development of the reading and writing skills of an autistic nursery school boy. However, in order to prove the effectiveness of differentiated instruction the researchers carried out a short post-test, which included four activities based on the lesson plans and interviews (after the intervention) of the mother, the nursery school teacher and the special education teacher.

With regard to the post-test, in the first question the boy was asked to report the details of the story after one of the researchers narrated it to him and then to choose a way of writing the story from one of the ways he was taught (e.g. through the use of magnetic letters, plasticine, liquid chocolate, self-adhesive letters, crayons, watercolors, letters which he cut out from magazines, the PC, etc.). He was then asked to read the story. In the second question he was asked to write his name in any of the ways he had been taught during the intervention and at the same time to read it, while in the third question he was asked to copy the emotions presented in the flashcards in whichever way he wanted to copy them. At the same time, every time he wrote a word, he was also expected to be able to read it. Finally, in his fourth and last question he was asked to recognize and name the vegetables from the worksheet and then write the first letter of each one of them, in whichever way he wanted to write it (e.g. through the use of magnetic letters, plasticine, liquid chocolate, self-adhesive letters, crayons, watercolors, letters which he cut out from magazines, the $\mathrm{PC}$, etc.).
The results of the post-test proved the effectiveness of differentiated instruction. The activities were structured and based on the specific lesson plans implemented by the boy within the context of the action research. The student immediately recalled the content of all the activities and proceeded directly to their realization, which meant that he understood what he had been taught. Consequently, all four questions were completed successfully by the student. However, it is worth mentioning that during the post-test a five-minute break took place as the boy expressed his wish to rest.

With regard to the post-semi-structured interviews, the participants were asked to answer questions, which dealt mainly with the effectiveness of differentiated instruction. In particular, they were asked about the changes they had observed in the boy's writing and reading skills after the intervention and the role played by differentiated instruction in bringing about these changes. The participants responded, in detail, to the changes they had observed in the child's reading and writing skills but they also commented positively on the changes they had noticed in some other areas such as in his social development, his psychological development and his emotional development. In particular, it was mentioned that these changes mainly concerned the boy's willingness to read and write and to develop his writing and speaking skills, to enrich his vocabulary, to express his feelings, but also to improve his social relations with the people living around him.

\section{Limitations of This Research}

This research examines the effectiveness of differentiated instruction to a boy with Asperger in early childhood education, in other words this research limits itself to one boy only and this automatically creates a research gap as the results cannot be generalized [67]. At the same time, the heterogeneity of autism and its complexities do not permit generalizations in the implementation of its results [68]. However, the successful completion of the lesson plans and the activities which followed can be seen as a starting point for future research work to be conducted in the field of differentiated instruction.

\section{Proposals for Further Research}

For a more in-depth research into the effectiveness of differentiated instruction to students with Asperger in early childhood, it is proposed that one or more school classes should participate in order to apply differentiated instruction to a larger sample of students who are autistic. In addition, an interesting approach would be to investigate other variables that may influence the attitudes and teaching choices of teachers in early childhood education, such as those which relate to policies which promote 
co-operation amongst teachers of different disciplines, as well as the presence of necessary tools, materials and infrastructure in schools.

An equally important and interesting proposal would be to offer better educational prospects to pupils with special education needs through the collaboration of nursery school teachers with special education teachers, or with occupational therapists, or speech therapists, etc. Finally, in the present study the lesson plans were based on the principles of differentiated instruction and focused mainly on the teaching of reading and writing skills to the specific boy with autism, it would thus be interesting to investigate other school subjects such as, for example, mathematics, music, etc., as well as other skills (such as listening and speaking skills).

\section{Concluding Remarks}

To conclude this research, it should be stressed that, every modern society should visualize the formation of a modern and democratic school which is open to ideas but which is also open to global developments in the field of knowledge. In order to achieve the 'construction of a school for all' it is necessary to intervene as early as possible to accurately assess the potential weaknesses of each student, to support the school environment and to implement specific training programs that meet the individual needs of each student. This necessitates knowledge of new pedagogical methods and approaches to teaching, one of which is differentiated instruction, and is brought about by the adequate training of teachers and their continuous support, the appropriate equipment which the school needs, and the adaptation of the curriculum to meet the needs of the students [50,36, 69,73].

Therefore, the school should be an institutional body which will accept all students no-matter what their needs and peculiarities are without categorizing, marginalizing and excluding some of these students from the right to education [70]. Last but not least the cooperation of all scientists and scholars is decisive in improving the lives of people with autism in the sense that they strive to give them equal treatment in society and to help them participate actively in all walks of life and in all areas of human activity $[71,72]$.

\section{Acknowledgements}

We are very grateful to the participants of this research, especially to the protagonist, the young boy with autism.

\section{REFERENCES}

[1] M. Gurian, P. Henley, T. Trueman, Boys and girls learn differently: A guide for teachers and parents. Jossey-Bass, San Francisco, 2001

[2] L. Santamaria. Culturally Responsive Differentiated Instruction: Narrowing Gaps Between Best Pedagogical. Practices Benefiting All Learners. Teachers College Record, Vol. 111, No. 1, 214-247. 2009

[3] C.A. Tomlinson. Grading for success. Educational Leadership, Vol. 58, No. 6, 12-15. 2001.

[4] R. Grumbine, P.B. Alden. Teaching science to students with learning disabilities. The Science Teacher, Vol. 73, No. 3, $26-31,2006$.

[5] A. A. Darrow. Students with learning disabilities in the music classroom. General Music Today, Vol. 26, No. 1, 41-43, 2012.

[6] J. Tuttle. Differentiated Classrooms. Cedar Mountain Academy. Woodbury, 2000.

[7] C.A. Tomlinson, M.B. Imbeau. Leading and managing a differentiated classroom. VA, ASCD, Alexandria, 2010.

[8] C.A. Tomlinson, T. R. Moon. Assessment and Student Success in a Differentiated Classroom. Va.: ASCD, Alexandria [2013]. ISBN-13: 978-1-4166-1617-7

[9] L. Kyriakides. Generic and Differentiated Models of Educational Effectiveness: Implications for the Improvement of Educational Practice. In: International Handbook of School Effectiveness and Improvement, 41-56, 2007.

[10] C.A. Tomlinson, C. Brighton, H. Hertberg. Differentiating Instruction in Response to Student Readiness, Interest, and Learning Profile in Academically Diverse Classrooms: A Review of Literature. Vol. 27, No. 2-3, 119-145, 2003. https://doi.org/10.1177/016235320302700203.

[11] Law.3699/2008 (Government Gazette 199 -A- 2-10-2008) Special education and training for persons with disabilities or special educational needs. [Internet] Available at: http://www.pischools.gr/special_education_new/ftp/nomoi /Nomoi-EA/N.\%203699\%20-\% $\overline{2} 02008 \% 2 \overline{0}-\% 20$ FEK.\%2 0199\%20-qA-\%202 -10-2008.pdf.

[12] A. Zoniou-Sideri, A. Vlachou. Greek teacher's belief systems about disability and inclusive education. International Journal of Inclusive Education, Vol. 10, No. 4/5, 379-394. 2006.

[13] B. Chamak, B. Bonniau, L. Oudaya, A. Ehrenberg. The autism diagnostic experiences of French parents. Autism, Vol. 15, No. 1, 83-97, 2011.

[14] C. Alexiou. Autism: The problem and its treatment in Greece. In I. Vogindroukas, G. Kalomiris and V. Papageorgiou (ed.) Autism. Stances and approaches. pp. 65-94. Traveler. Athens. 2007. (Translation from Greek).

[15] W. L. Heward, S. R. Alber-Morgan, M. Konrad. Exceptional Children: An Introduction to Special Education. What's New in Special Education (11th Edition), Pearson. ISBN-13: 978-0134027111.

[16] American Psychiatric Association Diagnostic and statistical manual of mental disorders: DSM-5 (5th ed.). American Psychiatric Publishing. Arlington, TX. 2013. 
[17] R. Jordan, S. Powell. Understanding and Teaching Children with Autism. Hellenic Society for the Protection of Autistic People, Athens. 2000 (Translation from Greek).

[18] A.M. Wetherby, B.M. Prizant. Introduction to autism spectrum disorders. In A. M. Wetherby \& B. M. Prizant (Eds.), Autism Spectrum Disorders: A transactional developmental perspective, pp. 1-7. Paulh Brookes Publishing, Baltimore, 2000.

[19] E. Fernell, C. Gillberg. Autism spectrum disorder diagnoses in Stockholm preschoolers. Research in Developmental Disabilities, No. 3, 680-685. 2010.

[20] H. Leonard, G. Dixon, A.J.O. Whitehouse, J. Bourke, K. Aiberti, N. Nassar, C. Bower, E.J. Glasson. Unpacking the complex nature of the autism epidemic. Research in Autism Spectrum Disorders, No. 4, 548-554, 2010.

[21] K. Loveland, B. Tunali-Kotoski, The school-age child with an autistic spectrum disorder. In F. Volkmar, R. Paul, A. Klin, D. Cohen (Eds.), Handbook of autism and pervasive developmental disorders: Volume 1 Diagnosis, development, neurology and behavior, pp. 247- 287. John Wiley \& Sons, New Jersey, 2005.

[22] V.A. Green, J. Sigafoos, M. O’Reilly, K.A. Pituch, R. Didden, G.E. Lancioni, et al. Behavioral flexibility in individuals with autism: Theory, assessment, and intervention. In L. B. Zhao (Ed.), Autism research advances, pp. 63-77. Nova Science. New York. 2007.

[23] A. Gena, E. Papadopoulou, S. Loukrezi, P. Galanis. The play of children with autism: Theory, assessment, and research on treatment. In L. B. Zhao (Ed.), Autism research advances, pp. 1-40. Nova Science. New York. 2007.

[24] S.J Rogers, I. Cook, A. Meryl. Imitation and play in autism. In F. Volkmar, R. Paul, A. Klin \& D. Cohen (Eds.), Handbook of autism and pervasive developmental disorders. Volume 1: Diagnosis, development, neurology and behavior, pp. 382-405, John Wiley \& Sons, New Jersey, 2005.

[25] A. Carter, N. Davis, A. Klin, F. Volkmar. Social development in autism. In F. Volkmar, R. Paul, A. Klin and D. Cohen (Eds.), Handbook of autism and pervasive developmental disorders, Volume 1: Diagnosis, development, neurology and behavior. pp. 312-334, John Wiley \& Sons. New Jersey. 2005.

[26] A.M. Grabrucker, Environmental factors in autism. Frontiers in Psychiatry, No. 3, 118. 2013.

[27] C.A. Pardo, D.L. Vargas, A.W. Zimmerman. Immunity, neuroglia and neuroinflammation in autism. International Review of Psychiatry, Vol. 17, No. 6,485-495. 2005.

[28] M. Rutter. Genetic influences and autism. In F. Volkmar, R. Paul, A. Klin and D. Cohen (Eds), Handbook of autism and pervasive developmental disorders. Diagnosis, development, neurology and behavior. Vol. 1 425-452. John Wiley \& Sons. New Jersey. 2005.

[29] D. Zafeiriou, A. Ververi, E. Vargiami. Childhood autism and associated comorbidities. Brain and development, Vol. 29, No. 5, 257-272. 2007.

[30] H. Gardener, D. Spiegelman and S.L. Buka. Perinatal and neonatal risk factors for autism: a comprehensive meta-analysis. Pediatrics, Vol. 128, No. 2, 344-355, 2011.

[31] T.C. Theoharides. Is a Subtype of autism an allergy of the Brain? Clinical therapeutics, Vol. 35, No. 5, 584-591., 2013.

[32] E. Sulukou. A case study on coping with the reading difficulties of a pupil with autism at pre-school age. Reading Difficulties: Good Practices and Effective Interventions, 117-138. [Internet] Available at: https://ww w.mathisiakesdyskolies.gr/system/tdf/articlefiles/8 soyloy koy_1.pdf?file $=1 \&$ type $=$ field_collection_item\&id=160\&fo rce. (Translation from Greek).

[33] R. Marzano. What works in schools. Association for Supervision and Curriculum Development. Alexandria, VA. 2003.

[34] A. Brouzos, F. Kosivakis. 'Open' teaching as an opportunity for Critical Communicative Teaching. In $\mathrm{H}$. Matsangouras (ed.) The Evolution of Didactics, 325-357. Gutenberg, Athens, 2006 (Translation from Greek).

[35] A. Gagatsis, M. Koutselini. Curriculum development as praxis and differentiation in practice: The case of mathematics. In A. Gagatsis (Ed.) A multidimensional approach to learning in mathematics and sciences. Nicosia, 107- 122, 2000 (Translation from Greek).

[36] P. Subban. Differentiated instruction: A research basis, International Education Journal, Vol. 7, No. 7, 935-947, 2006.

[37] C.A. Tomlinson, C.C. Edison. Differentiation in practice: a resource guide for differentiating curriculum. ASCD, Alexandria, VA, 2003.

[38] A. Loizidou, M. Koutselini. Metacognitive monitoring: A key and an obstacle to effective learning. Teachers and Teaching, Vol. 13, No. 5, 499-521, 2007.

[39] J. Dodge. Differentiation in action. Scholastic Inc, New York, 2005

[40] M. Corley. (2008) Differentiated Instruction Adjusting to the Needs of All Learners. [Online] Available at: http://www.ncsall.net/?id=736, 2008.

[41] C.A. Tomlinson. Differentiation of Instruction in the Elementary Grades, Eric Digest, [Online] Available: http://www.ericdigests.org/2001-2/elementary.html, 2004.

[42] P. Theroux. (2004) Strategies for Differentiating. [Online] Available on: http://members.shaw.ca/priscillatheroux/diff erentiatingstrategies.html, 2004.

[43] C. Chapman, R. King. Differentiated assessment strategies. Corwin Press, Thousand Oaks, CA, 2005.

[44] F. Antoniou. Improving reading comprehension in students with special educational needs. Shaker Verlag, Aachen, 2006.

[45] B.K. Taylor. Content, Process, and Product: Modeling Differentiated Instruction. Kappa Delta PiRecord, Vol. 51, No. 1, 13-17, 2015.

[46] K.W. Howell, V. Nolet. Tools for assessment. Curriculum-Based Evaluation, Teaching and Decision Making, 2000. 
[47] T.R. Moon. The role of assessment in differentiation. Theory into Practice, Vol. 4, No. 3. 2005.

[48] I. Salvaras Language Teaching for All Students. Self-publishing. Athena. 2000.

[49] D. Blaz. Differentiated assessment for middle and high school classrooms. Eye of Education, New York, 2008.

[50] C.A. Tomlinson. Making a difference. [Online] Available: http://www.edweek.org/tsb/articles/2008/09/10/01 tomlinso n.h02.html, 2008.

[51] M. Koutselini. Listening to students' voices for teaching in mixed ability classrooms: Presuppositions and considerations for differentiated instruction. Learning and teaching, Vol. 1, No. 1, 17-30, 2008.

[52] C. Tomlinson, S. Allan. Leadership for Differentiating Schools \& Classrooms. ASCD, 2011.

[53] L. Cohen, L. Manion, K. Morrison. Research Methods in education: Available at: http://knowledgeportal.pakteacher s.org/sites/knowledgeportal.pakteachers.org/files/resources /RESEARCH\%20METHOD\%20COHEN\%20ok.pdf

[54] I. Hay. Qualitative Research Methods in Human Geography. North Melbourne. Oxford University Press, 2000.

[55] N.K. Denzin, Y.S. Lincoln. Handbook of Qualitative Research, Thousand Oaks, 2nd Ed. Sage, California, 2000.

[56] C. Robson. Real World Research, Gutenberg, Athens, 2007 (Translation from Greek).

[57] M. Koutselini, P. Persianis. Theory - practice Divide in Teacher Education at the University of Cyprus and the Role of the Traditional Values. Teaching in Higher Education, Vol. 5 No. 4, 501-520, 2000.

[58] E. Ferrance, Themes in education. Action research. LAB: a program of The Education Alliance. Northeast and Islands Regional Educational Laboratory at Brown University. [Online] Available at: https://www.brown.edu/academics/e ducationlliance/sites/brown.edu.academics.education-allia nce/files/publications/act_research.pdf, 2000.

[59] G.E. Mills. Action research: a guide for the teacher researcher (2nd ed.), Upper Saddle River, Merrill/Prentice Hall, NJ. 2003.

[60] G.J. Pine. Teacher Action Research: Building Knowledge Democracies. Sage Publications, 2009.

[61] M. Patton. Qualitative research and evaluation methods. Sage Publications, California, 2002.

[62] D. M. Mertens. Transformative Mixed Methods Research. Qualitative Inquiry, Vol. 16, No. 6, 469-474 https://doi.org /10.1177/1077800410364612

[63] S. M. Nolas. Pragmatics of pluralistic qualitative research. In N. Frost (ed.), Qualitative research methods in psychology: Combining core approach. Open University Press, Berkshire, 2011.

[64] D. Howitt. Introduction to qualitative methods in psychology. Pearson Education Limited, Harlow, 2010.

[65] V. Braun, V. Clarke. Using thematic analysis in psychology. Qualitative Research in Psychology, Vol. 3, No. 2. pp. 77-101, 2006.
[66] F. Gerovasiliou, M. Zafiri. Adapting Board Games to Stimulate Motivation in Vocabulary Learning in Six-Year-Old Learners. A Case Study. Journal of Studies in Education. Macrothink Institute. Vol. 7, No. 3, 2017.

[67] T. Anisimova, S.B. Thomson. Using multi-method research methodologies for more informed decision making. JOAAG, Vol. 7. No.1, 2012.

[68] T. Bourgeron. Current knowledge on the genetics of autism and propositions for future research. Vol. 339, No. 7-8, 300-307. 2016.

[69] N. Bosch. Differentiated Curriculum. [Online] Available at: http://www.adifferentplace.org/differentiated.htm, 2001.

[70] T. Booth, M. Ainscow, K. Black - Hawkins, M. Vaughan and L. Shaw. Index for Inclusion: Developing Learning and Participation in Schools. CSIE (Centre for Studies in Inclusive Education) Bristol, 2000.

[71] L.A. Ruble, J.H. McGrew. Community services outcomes for families and children with autism spectrum disorders. Research in Autism Spectrum Disorders, Vol. 1 No. 4, 360-372, 2007.

[72] E.H. Finke, K.D.R. Drager, and S. Ash. Pediatricians' perspectives on identification and diagnosis of autism spectrum disorders. Journal of Early Childhood Research, Vol. 8, No. 3, 254-268. 2010.

[73] M.N. Lavine. Leiter International Performance Scale: A handbook. Chicago, IL: Stoelting Company. 1983. 